\title{
Ultrasonography of normal, cystic and dysplastic kidney in cattle
}

\author{
M. M. Seif ${ }^{1^{*}}$, H. A. Bakr ${ }^{2}$ \\ ${ }^{1}$ Surgery, anesthesiology and radiology department, Faculty Veterinary Medicine, Beni-Suef University, \\ Beni-Suef, Egypt \\ ${ }^{2}$ Internal Medicine department, Faculty Veterinary Medicine, Beni-Suef University, Beni-Suef, Egypt
}

\begin{abstract}
Thirty four apparently healthy cattle (9 males and 25 females) of mixed breed (Balady X Friesen) were selected for ultrasonographic investigations in this study. Ultrasonographic measurements of vertical and horizontal diameters of kidney, the diameters of the renal parenchyma and the diameter of renal sinus were determined in the middle of right and left kidneys. Twenty nine cattle $(9$ males and 20 females), had normal ultrasonographic appearance of both right and left kidney while the other five cows had some pathological affections including cystic kidney and renal dysplasia in their left kidneys . The vertical diameter of the right kidney was $(4.84 \pm 1.18 \mathrm{~cm})$, the horizontal diameter $(9.16 \pm 1.35 \mathrm{~cm})$, and the vertical diameter of the renal sinus was $(3.54 \pm 1.02 \mathrm{~cm})$. The thickness of the renal cortex and medulla ( renal parenchyma) was $(2.16 \pm 0.46 \mathrm{~cm})$. On the other hand ,the vertical diameter of the left kidney was $(5.89 \pm 1.13 \mathrm{~cm})$, and the vertical diameter of the renal sinus was $(3.83 \pm 1.12 \mathrm{~cm})$. The thickness of the renal cortex and medulla (renal parenchyma) was $(2.46 \pm 0.35 \mathrm{~cm})$. It was concluded that the ultrasonographic values determined in this study can be used as references for the diagnosis of morphologic changes in the kidney of domestic dairy cattle.
\end{abstract}

Ultrasonography has become increasingly important technology for examination of anatomy and physiology of kidneys. It is used to establish the standards of renal measurements including; length, width, and height (Jarretta et al., 2004). Also, it supplemented the clinical examination and clinicopathological analysis by providing additional information on renal diseases (Floeck, 2007).

Macroscopically, kidneys of cattle can be divided into three layers as the capsule, parenchyma and sinus. Renal parenchyma has a cortex and a medulla. The medulla possesses 8 or 10 pyramids depending on the animal species. Pelvis renalis is missing in cattle. Urine flows from renal papillae through the calices. The right kidney is located on the ceiling of the abdomen, stuck between the last costae and processus transversus of the $2^{\text {nd }}$ and $3^{\text {rd }}$ lumbar vertebras. Ventral surface faces the liver, pancreas, duodenum and colons. Whereas the left kidney is situated backwardly and underneath the right kidney that can move towards the medial site depending on the rumenal filling (Braun, 1991, 1993).
Ultrasonography is often the initial imaging technique for the detection of renal affections, because it can be performed safely even when kidney function is impaired. It is noninvasive, painless, and requires no radiopaque dye. Ultrasound scans provide some indirect information about kidney functions, an excellent way to estimate kidney size and position, readily detect obstruction, and help to diagnose structural abnormalities. Ultrasonography is particularly useful in distinguishing a simple benign (noncancerous) cyst from a more complex cyst, or a solid mass that may be cancerous. It is used to locate the best place for a kidney biopsy (Tyler et al., 1991; Hirsbrunner et al., 1996; Rademacher, 2005; Braun et al., 2007a ; Merck, 2007) .

Ultrasonography used for Identification of changes in kidney associated with urolithiasis; characterization of findings in cases with bacterial pyelonephritis, hydronephrosis and renal amyloidosis; Evaluation of both kidneys before unilateral nephrectomy (bacterial pyelonephritis or hydronephrosis) and Percutaneous ultrasoundguided biopsy of the kidney (Hayashi et al., 1994; Gufler, 1999; Braun, 2004 and Braun et al.,

* Corresponding author. Tel.: +20 127456156; fax: +20822327982 .

E-mail address: seif_th2003@yahoo.com (M. M. Seif). 
2007b). Ultrasonography helped to determine kidney disease severity, to direct the course of treatment, and to improve the accuracy of diagnosis and prognosis (Hayashi et al., 1994).

The purpose of the present study was to determine the dimensions and structure of both right and left kidneys and to detect either some clinically or non-clinically diagnosed renal abnormalities in cattle by using of ultrasonography.

\section{Materials and Methods}

In the farm of faculty of Veterinary Medicine, Beni-Suef University, thirty four apparently healthy cattle (9 males and 25 females) of mixed breed (Balady X Friesen) were selected for this study. The weights of the animals were ranged from $380-550 \mathrm{~kg}$ and their age ranged from $2.5-$ 5 years.

A portative ultrasound (240 PARUS VET Pie Medical Equipment. B.V. Philipsweg 16227 Maastricht. The Netherlands) was used for ultrasonographic examination, in this study. Two types of transducers were used, curved array electronic transducer (3.5/5.0 $\mathrm{MHz})$ for examination of right kidney and linear array transducer $(6.0 / 8.0 \mathrm{MHz})$ for examination of left kidney. Feed and water were withheld for at least $12 \mathrm{~h}$. before examination. All animals were examined in standing position.

Percutaneous transabdominal ultrasonographic examination of right kidney. The areas over the intercostal space between T12 and T13, the lumbar region, and in the para-lumbar fosse on the right side of the animals were shaved. Transmission gel was applied, and the right kidney was examined with 3.5 - and 5.0-MHz convex transducer. The transducer was placed in the region between T13 and $\mathrm{L} 1$, and in the lumbar region (between the lumbar vertebrae in the areas from L1 to L3), and in the area of para-lumbar fosse. The transducer was held at the right angles to the midline for imaging right kidney transversally. When the transducer was held parallel to the vertebral column (mainly in the para-lumbar fosse), the kidney was imaged longitudinally. The measurements were made, using the sagital and transverse ultrasonograms (in the area between L1 and L2), and using ultrasonograms in the area of para-lumbar fosse with the transducer in the horizontal position according to Braun (1991). The vertical and horizontal diameters of the kidney, the diameters of the renal parenchyma (renal cortex and medulla), and the renal sinus were determined in middle of the right kidney.

Transrectal ultrasonographic examination of left kidney. After removing rectal content the transducer was covered with jelly and placed in a shoulder glove that was used by the applicator. After internal palpation of the left kidney the transducer is held in the hand and introduced cranially into the rectum. The transducer (6.0/8.0 $\mathrm{MHz}$ linear array probe) was placed in the lumen of the rectum parallel to the vertebral column and above the left kidney. The vertical diameter, the diameters of the renal parenchyma and the diameter of renal sinus were determined in the middle of the left kidney according to (Ozturk et al., 2005).

Statistical analysis. The statistical calculation (mean and standard deviation) of the vertical and horizontal diameters, the diameters of the renal parenchyma and the diameter of renal sinus were performed using PC-stat, Version 1A program according to (Mohan et al., 1985).

\section{Results}

The results of the ultrasonographic examination showed that 29 cattle ( 9 males and 20 females), had normal ultrasonographic appearance of both right and left kidneys while the other five cows had some pathological affections in their left kidneys.

Ultrasonographic results of normal kidney. The echo pattern of normal organs was usually specific. The lobulation of the kidney could be visualized ultrasonographically. Various structures of the kidneys including the renal pyramids, renal parenchyma and renal sinuses were identified in different echogenic images. The parenchyma of the kidney was hypoechoic, whereas the sinus was hyperechoic. No image of ureter was produced (Fig. 1,3). The cortex and medulla of the right kidney could not be differentiated (Fig. 1). The renal cortex was hyperechoic in comparison to the relative hypoechoic renal medullary pyramids in left kidney (Fig. 3).

In the right kidney, the vertical diameter was $(4.84 \pm 1.18 \mathrm{~cm})$, the horizontal diameter was $(9.16 \pm 1.35 \mathrm{~cm})$, and the vertical diameter of the renal sinus was $(3.54 \pm 1.02 \mathrm{~cm})$. The thickness of the renal cortex and medulla (renal parenchyma) was $(2.16 \pm 0.46 \mathrm{~cm})$. The medullary pyramids could be visualized when the transducer was 


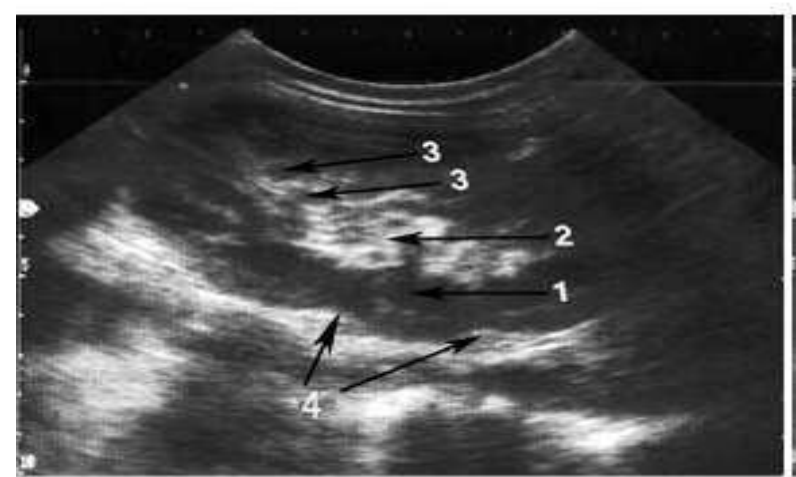

Fig. (1): Normal right bovine kidney 1:Renal parenchyma

2:Renal sinus

3:Renal pyramids

4:Renal lobulation

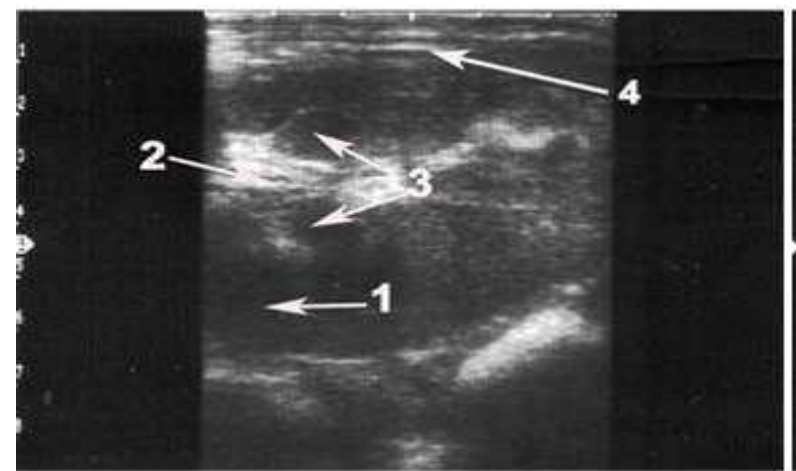

Fig. (3): Normal left bovine kidney 1:Renal parenchyma 2:Renal sinus 3 4:Renal lobulation

placed in the paralumbar fossa (Fig. 2). On the other hand, in the left kidney, the vertical diameter was $(5.89 \pm 1.13 \mathrm{~cm})$, and the vertical diameter of the renal sinus was $(3.83 \pm 1.12 \mathrm{~cm})$. The thickness of the renal cortex and medulla (renal parenchyma) was $(2.46 \pm 0.35 \mathrm{~cm})$ (Fig. 4).

Ultrasonographic results of abnormal kidney. Five animals were diagnosed ultrasonographically as unilaterally abnormal left kidney. In three animals, although the ultrasonographic kidney measurements appeared normal in both kidneys, ultrasonographic cystic lesions were found in the left kidney. The renal sinus of the affected kidney was hyperechogenic. The sonographic feature of renal cysts include: a round to ovoid contour, anechoic contents, smooth sharply demarcated thin walls with a distinct far wall border, and strong

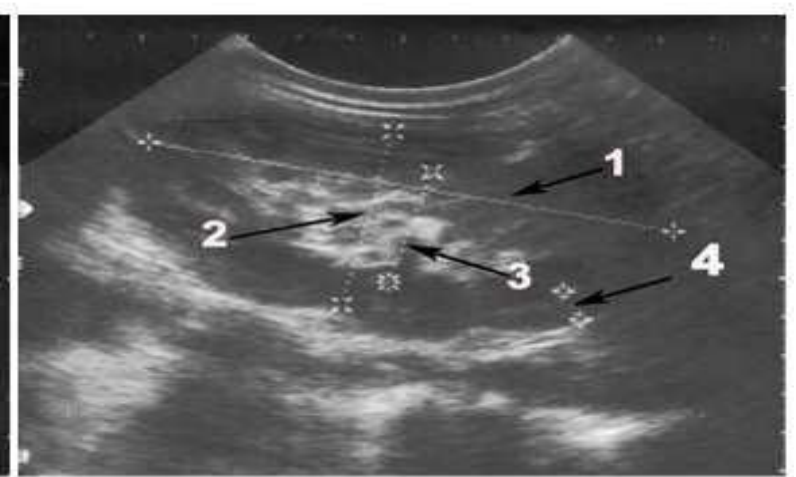

Fig. (2): Normal right bovine kidney 1:Horizontal diameter 2:Vertical diameter

3:Vertical diameter of renal sinus 4:Thickness of renal parenchyma

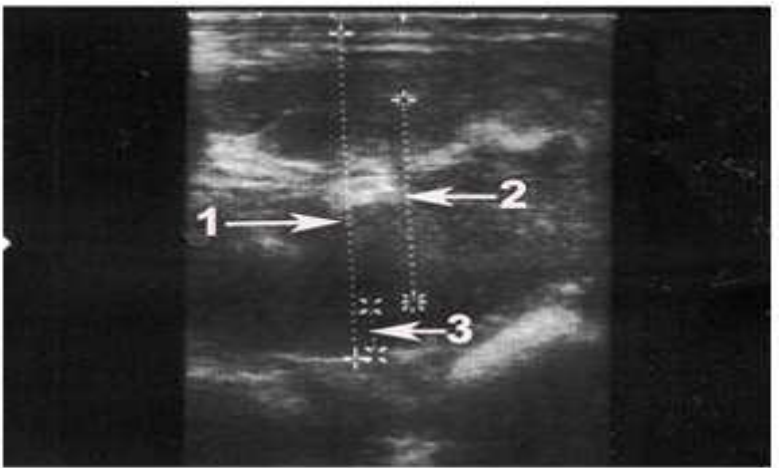

Fig. (4): Normal left bovine kidney 1:Vertical diameter

2:Vertical diameter of renal sinus

3:Thickness of renal parenchyma

distal acoustic enhancement (through transmission) (Fig. 5). The vertical diameter of the kidney was $(5.58 \pm 0.8 \mathrm{~cm})$, and the vertical diameter of the renal sinus was $(3.5 \pm 0.56 \mathrm{~cm})$. The thickness of the renal cortex and medulla (renal parenchyma) was $(1.13 \pm 0.6 \mathrm{~cm})$. The diameter of the cysts varied from $1.10-1.13 \mathrm{~cm}$ (Fig. 6).

Rectal palpation of the other two animals showed signs of left kidney dysplasia characterized by small sized kidney, and loss of renal lobulation. Ultrasonographically, the dysplastic kidney (Fig. 7, 8) had 3 abnormal ultrasonographic findings; loss of normal renal echogenicity of the renal parenchyma (hyperechoic), decreased ultrasonographic kidney measurements, and corticomedullary cysts in one 


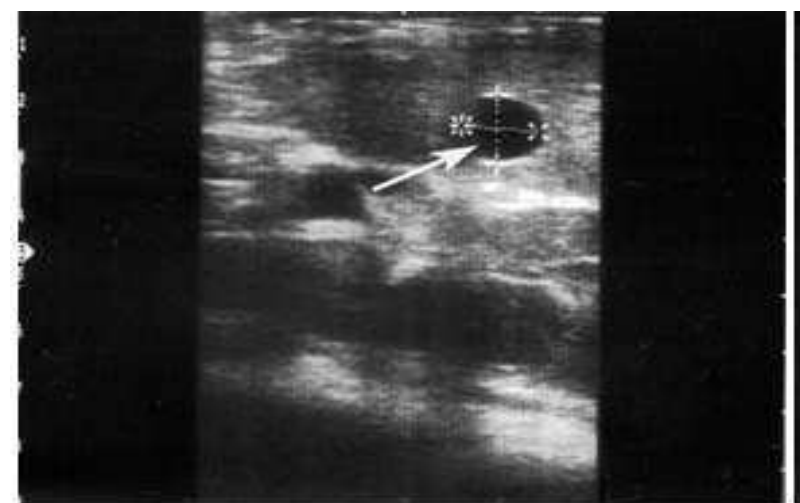

Fig.(5): Renal cyst (arrow)

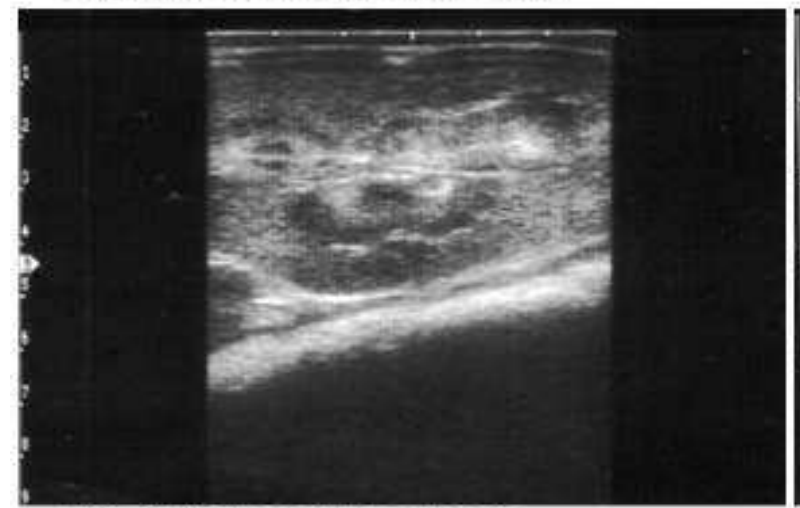

Fig.(7): Renal dysplasia

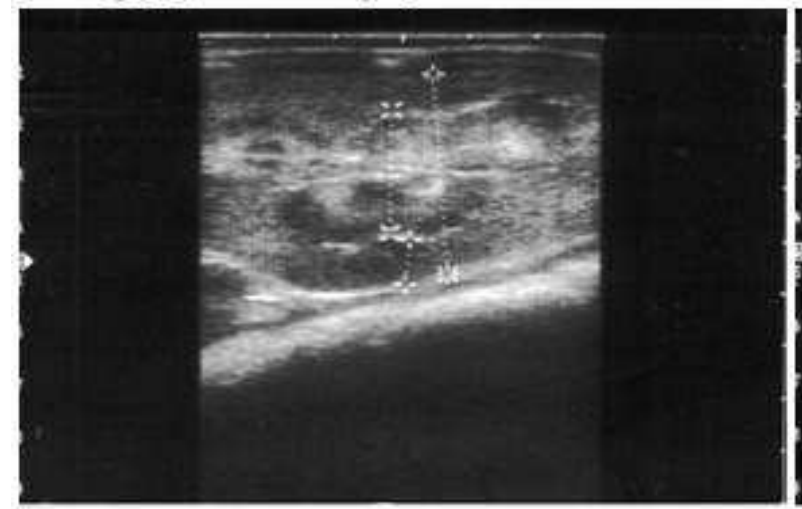

Fig.(9): Renal dysplasia sonogram

case (Fig. 10). The vertical diameter of the kidney was $(4.23 \& 4.13 \mathrm{~cm})$, and the vertical diameter of the renal sinus was $(3.20$ and $2.78 \mathrm{~cm})$. Thethickness of the renal cortex and medulla (renal parenchyma) was (1.12 and $0.98 \mathrm{~cm})$ (Fig.9).

\section{Discussion}

Ultrasonography is an integral part of contemporary bovine medicine (Braun, 2004). Kidney Ultrasonography, in cattle, was used for

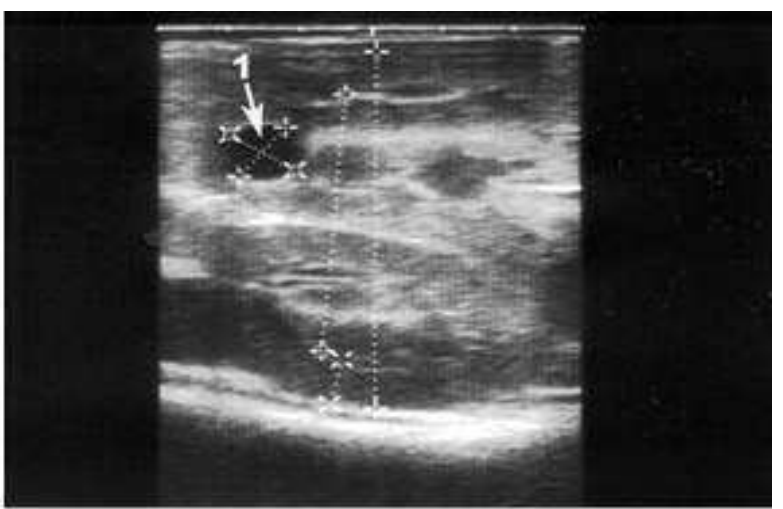

Fig.(6): Renal cyst sonogram

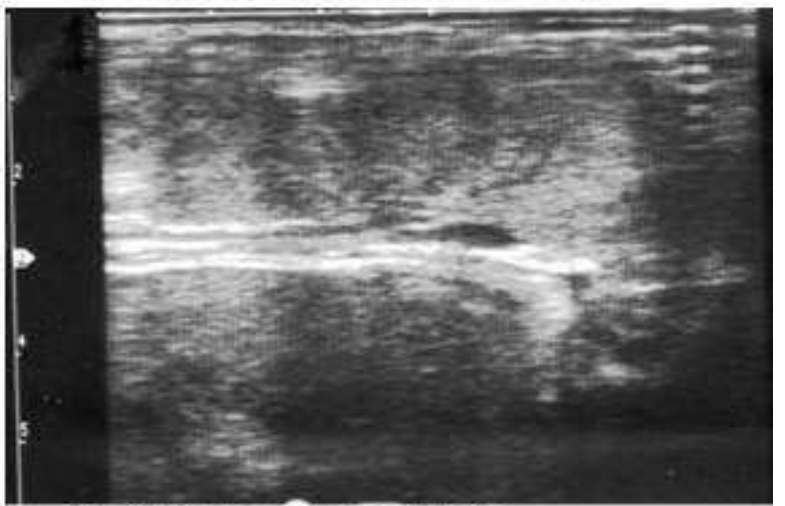

Fig.(8): Renal dysplasia

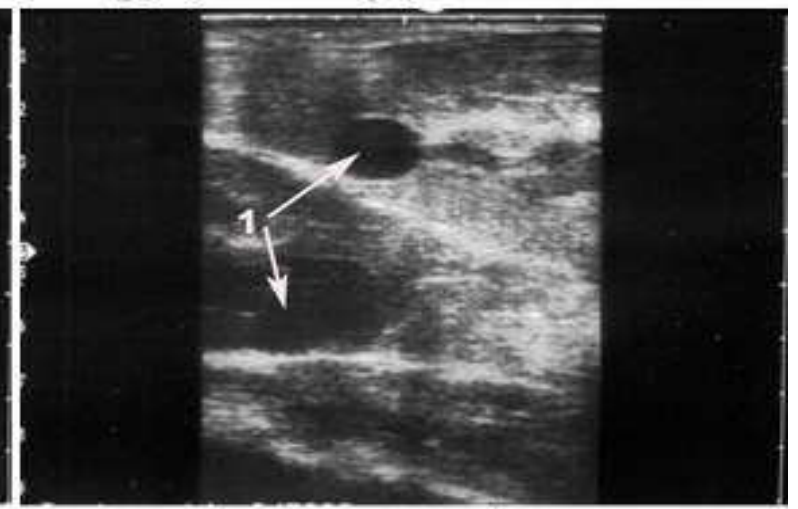

Fig.(10): Renal dysplasia with cyst

evaluation of the dimensions and appearance of the renal medulla, cortex and pelvis (Braun, 1991 ,1993 and Abidari et al., 2002). The routine sonographic imaging protocol, using standard anatomic planes, enabled each kidney to be examined in its entirety. The protocol provided definition of normal renal sonographic anatomic features and may permit a more informed interpretation of renal images and accurate recognition of renal pathologic change (Hoffmann 
et al., 1995; Chuang and Tsai, 1998; Hoffmann et al., 2000).

Feed and water were withheld for at least 12 hours before examination to minimize the gas content in the rumen and intestine as the gas interferes the Ultrasonographic viewing. (Abuzaid, 1995)

In principle, the depth of penetration of the sound waves and the resolution are inversely related; a low frequency is associated with greater penetration and lower resolution, and vice versa. For most diagnostic work, a $3.5 \mathrm{MHz}$ transducer provides adequate depth and good resolution. Structures close to the surface of the body are examined with a $5.0,7.5$ or even $10.0 \mathrm{MHz}$ transducer (Braun, 2004). This explains the use of curved array transducer $(3.5 / 5.0 \mathrm{MHz})$ for percutaneous transabdominal ultrasonographic examination of right kidney and the linear array probe $(6.0 / 8.0 \mathrm{MHz})$ for transrectal examination of the left kidney. The use of these different transducers depends on the thickness of the abdominal wall and perirenal fat.

Percutaneous transabdominal ultrasonographic examination method was used to examine right kidney and transrectal ultrasonographic examination was used to examine left kidney. This is due to the difference of the anatomical position of right and left kidneys. Because the left kidney hangs in the abdominal cavity and had long distance from body surface, so it can't be examined ultrasonographically via percutaneous transabdominal method. On the other hand, It is difficult to examine the right kidney by transrectal ultrasound because of its anatomical position; therefore detailed examination may be achieved by percutaneous transabdominal approach. This was agreed with (Braun 1991,1993; Mueller et al. 1999). Meanwhile, Ozturk et al. (2005) recorded that both right and left kidneys could be examined via transrectal ultrasound method. They added that the detailed examination of the right kidney was not practical by using this approach.

Ultrasonographically, the lobulation of the kidney could be visualized, various structures of the kidneys including the renal pyramids, renal parenchyma and renal sinuses were identified in different echogenic images. These results were in agreement with (Braun 1991; 1993).

Wood (1990) and Churchill (1999) in their studies in dogs found that the renal medulla was always hypoechoic compared to the cortex, uniformly mottled echogenicity of the renal cortex could be clearly differentiated from the less echogenic renal medulla. In this study, the renal cortex was hyperechoic in comparison to the relative hypoechoic renal medullary pyramids in left kidney, however, the cortex and medulla could not be differentiated in right kidney. This may be attributed to the use of different transducers with different resolution results for the right and left kidneys, these results were in agreement with (Braun, 1991,1993).

Prior to the use of ultrasound, renal dimensions were obtained by excretory urography, but had the disadvantages of magnification, diuretic effect of contrast material and patient exposure to ionizing radiation (Han and Bobcock, 1985). Ultrasonography has provided a reliable, noninvasive, and relatively inexpensive method for the measurement of kidney size (Schmidt, et al., 2004; Rabelo et al., 2006). It was concluded that relative changes in renal size can be easily monitored with ultrasound (Nyland, 1997).

The measurements of the left normal kidney were more than the right kidney; this agreed with (Braun 1991,1993). The vertical diameter of the left kidney was $(5.89 \pm 1.13 \mathrm{~cm})$ and the vertical diameter of the renal sinus was $(3.83 \pm 1.12 \mathrm{~cm})$. The thickness of the renal cortex and medulla (renal parenchyma) was $(2.46 \pm 0.35 \mathrm{~cm})$. On the other hand, the vertical diameter of the right kidney was $(4.84 \pm 1.18 \mathrm{~cm})$ and the vertical diameter of the renal sinus was $(3.54+1.02 \mathrm{~cm})$. The thickness of the renal cortex and medulla (renal parenchyma) was $(2.16 \pm 0.46 \mathrm{~cm})$,

The renal measurements, in this study, were slightly differing than those of (Braun 1991,1993; Ozturk et al., 2005). Braun (1991) and (1993) reported that the vertical diameter of the left kidney was $(6.2 \pm 1.0 \mathrm{~cm})$ in the region of the renal hilus. The diameter of the renal sinus varied from $(1.1 \mathrm{~cm})$ to $(2.5 \mathrm{~cm})$. The thickness of renal cortex and medulla was between $(2.0 \mathrm{~cm})$ and $(2.3$ $\mathrm{cm})$. The vertical diameter of the right kidney was $(5.1 \pm 0.47 \mathrm{~cm})$, the horizontal diameter $(9.4 \pm$ $0.98 \mathrm{~cm})$. The thickness of the renal cortex and medulla was between $(1.9 \mathrm{~cm})$ and $(2.1 \mathrm{~cm})$. While Ozturk et al. (2005) mentioned that the mean vertical diameter of the kidney was (6.39 $\mathrm{cm})$. The mean horizontal diameter of the renal sinus $(4.52 \mathrm{~cm})$, the thickness of renal cortex and 
medulla was $(2.56 \mathrm{~cm})$ and the horizontal diameter was $(9.64 \mathrm{~cm})$. This indicates that the difference in kidney measurements in the different studies may be due to the different breeds used. Swiss Brownish breed in Braun's studies, Holstein breed in Ozturk's study and mixed breed (Balady X Friesian) in this study.

In context of investigated renal cyst in left kidney, Merck (2007) reported that, renal cysts are a prominent feature of several congenital systemic disorders. Congenital renal cystic dysplasias are commonly discovered by ultrasonography prenatally or during early childhood. Acquired renal cysts are simple cysts that must be distinguished from more serious causes of cystic disease. Acquired cysts are usually simple, i.e. they are round and sharply demarcated with smooth walls. They may be single or multiple. Single cysts are isolated (or few in number) and are most often detected incidentally. They are clinically insignificant but must be distinguished from other more significant cystic renal disorders and renal masses such as renal cell carcinoma, which is typically irregular or multiloculated with irregular walls, septae, and areas of unclear demarcation

In agreement with the present results, Maxi and Prescott (1993) stated that, the simple renal cysts occur sporadically in many species and are usually an incidental finding. This was supported by Deem and Whitlock (1982) who found 2 large simple renal cysts during left flank exploratory lapartomy in a cow. Besides, Konde et al. (1986) recorded that conventional radiography and intravenous urography are reportedly less sensitive than ultrasonography for detection of renal cysts. Using Ultrasonography, simple renal cysts are infrequently detected in cats (Walter et al., 1988) but in dogs simple renal cysts are reported to be common (Grooters and Biller, 1995).

Denoting to renal dysplasia diagnosed in this study, Ridson (1971) and Merck (2007) defined renal dysplasia as a type of familial renal disease characterized by abnormal differentiation of the metanephric parenchyma. It represents a collection of anomalies in which kidneys begin to form but then fail to differentiate into normal nephrons and collecting ducts. The renal vasculature, tubules, collecting ducts, or drainage apparatus develops abnormally.
Referring to the ultrasonographic findings of dysplastic kidney in this study, Picut and Lewis, (1987), Sasaki et al., (2002) and Okada et al. (2005) recorded that, in animals, the dysplastic kidneys had shrunk perceptibly and had greywhite radial streaks; microscopically they showed severe interstitial fibrosis with round-cell infiltration in the outer zone of the medulla and cortex, and reductions in the numbers of glomeruli and tubules. In the fibrotic areas there were immature epithelia with an irregular arrangement, and the basement membrane of the tubules was thickened. It was concluded that renal tubular dysplasia was the primary lesion of the disease, and that interstitial fibrosis and reductions in the numbers of nephrons were secondary lesions. In addition, Felkai et al., (1997) and Schulze et al. (1998) reported that, in dogs, the ultrasonographic findings of histologically confirmed renal dysplasia, revealed kidneys of significantly reduced volume. During qualitative evaluation, the ultrasound appearance, overall increased echogenicity with poor corticomedullary demarcation was noticed. Post-mortem histological diagnosis revealed renal dysplasia and secondary fibrosis. These results were near the results in this study.

In conclusion, Normal ultrasound images kidney diameters in mixed breed (Balady X Friesian) cattle were determined. The ultrasonographic values determined in this study can be used as references for the diagnosis of morphologic changes in the bovine kidney. Because abnormal renal sonographic findings can be seen long before the appearance of any clinical symptoms or signs, ultrasonography is the best technique for diagnosing kidney disease. From the preventive medicine point of view, it is possible to detect lesions located in the bovine kidney before clinical manifestations occur by ultrasound aided evaluation.

\section{References}

Abidari, J.M.; Park, K.H.; Kennedy, W.A. and Shortliffe, L.D. (2002): Follow-up of the contralateral renal size in children with multicystic dysplastic kidney. J. Urol. 2002, Oct; 168 (4 Pt 2):1821-1625.

Abuzaid, R.M. (1995): Radio and sonographic anatomical studies on the goat. MVSc thesis, Fac. Vet. Med., Suez Canal Univ. dept. Anat. Embryol.

Braun U (1991): Ultrasonographic examination of the right kidney in cows. Am. J. Vet. Res. 52 (12): 1933-1939. 
Braun, U. (1993): Ultrasonographic examination of the left kidney, the urinary bladder, and the urethra in cows Zentralbl Veterinarmed A. 40 (1): 1-9.

Braun U (2004): Diagnostic ultrasonography in bovine internal diseases. $23^{\text {rd }}$ World Buiatrics congress Quebec Canada, pp. 11-16.

Braun, U.; Nuss, K.; Sydler, T. and Lischer, C. (2007 b): Ultrasonographic findings in three cows with urethral obstruction due to urolithiasis. Vet. Rec. 159: 750-752.

Braun, U.; Nuss, K.; Wehbrin, D.; Rauch, S. and Pospischil, A. $(2007$ a): Clinical and ultrasonographic findings, diagnosis and treatment of pyelonephritis in 17 cows. Vet. J. pp. 13

Chuang, Y.F. and Tsai, T.C. (1998): Sonographic findings in familial juvenile nephronophthisis-medullary cystic disease complex. J. Clin. Ultrasound. 26 (4): 203-206.

Churchill, J.A.; Feeney D.A.; Fletcher, T.F.; Osborne, C.A.; Polzin, D.J. (1999): Age and diet effects on relative renal echogenicity in geriatric bitches. Vet. Radiol. Ultrasound. 40 (6): 642-647.

Deem, D.A. and Whitlock, R.M. (1982): Renal cysts in a cow with anorexia, hypocalcemia and abdominal pain. Cornell Vet. 72 (1): 36-42.

Felkai, C.; Voros, K.; Vrabely, T.; Vetesi, F.; Karsai, F. and Papp, L. (1997): Ultrasonographic findings of renal dysplasia in cocker spaniels: eight cases. Acta Vet. Hung. 45 (4):397-408

Floeck, M. (2007): Sonographic application in the diagnosis of pyelonephritis in cattle. Vet. Radiol. Ultrasound. 48 (1): 74-747.

Grooters, A.M. and Biller, D.S. (1995): Small animal practice. Saunders, Philadelphia, pp. 933-936.

Gufler, H. (1999): Nierenabszesse, Pyelonephritis und Zystitis purulenta bei einem 5 Monate alten Kalb diagnostiziert mittels Sonographie, Wiener Tierärztliche Monatsschrift 86: 247-251.

Han, B.K. and Babcock, D.S. (1985): Sonographic measurements and appearance of normal kidneys in children. Am. J. Res. 145: 611-616

Hayashi, H.; Biller, D.S.; Rings, D.M. and Miyabayashi, T. (1994): Ultrasonographic diagnosis of pyelonephritis in a cow. J. Am. Vet. Med. Assoc. 205 (5): 736-738.

Hirsbrunner, G.; Lang, J.; Nicolet, J. and Steiner, A. (1996): Nephrektomie nach chronischer, unilateraler, eitriger Pyelonephritis beim Rind. Tierärztliche Praxis. 24: 17-21.

Hoffmann, K.L.; Wood, A.K. and McCarthy, P.H. (1995): Sonographic-anatomic correlation and imaging protocol for the kidneys of horses. Am. J. Vet. Res. 56 (11): 1403-1412.

Hoffmann, K.L.; Wood, A.K.; McCarthy, P.H. (2000): Ultrasonography of the equine neonatal kidney. Equine Vet. J. 32 (2): 109-113.

Jarretta, G.B.; Bombonato, P.P.; Guimaraes, M.A. (2004): Renal ultrasonographic evaluation in the oncilla (Leopardus tigrinus). J. Zoo. Wild Med. 35 (3): 356-360.

Konde, L.J.; Park, R.D.; Wrigley, R.H. and Leble, J.L. (1986): Comparison of radiography and ultrasongraphy in the evaluation of renal lesions in the dog. J. Am. Vet. Med. Assoc. 188: 1420-1425.
Maxi, M.G.; and Prescott, J.F. (1993): Pathology of domestic animals $4^{\text {th }}$ edt. Vol. 2 academic press, San Diego, pp. 461-465.

Merck (2007): kidney and urinary tract disorders. Merck manual for diagnosis and therapy, copyright 2007, Merck \& co., inc.

Mohan, R.; Kathleen, B. and Marc, Z. (1985): Statistical program for microcomputers (PC-Stat, Version 1A). Dept. Food Science, the Georgia University, USA.

Mueller, P.; Hay, W.; Allen, D.; Collatos, C. and Watson, E. (1999): Removal of an ectopic left kidney through a ventral midline celiotomy in a calf. J. Am. Vet. Med. Assoc. 214 (4): 532-4, 496

Nyland, T.G.; Fisher, P.E.; Gregory, C.R. and Wisner, E.R. (1997): Ultrasonographic evaluation of renal size in dogs with acute allograft rejection. Vet. Radiol. Ultrasound. 38 (1): 55-61.

Okada, K.; Ishikawa, N.; Fujimori, K. Goryo, M.; Ikeda, M. Sasaki, J.; Watanabe, D.; Takasuga, A.; Hirano, T. and Sugimoto, Y. (2005): Abnormal development of nephrons in claudin-16-defective Japanese black cattle. J. Vet. Med. Sci. 67 (2): 171-178.

Ozturk, S.; Demirakn, A.; Kibar, M. Bumin, A. and Pekkaya, S. (2005): Transrectal Ultrasonographic Examination of the Urinary System in Holstein Cows. Turk J Vet Anim Sci. 29: 263-267.

Picut, C.A.; Lewis, R.M. (1987): Microscopic features of canine renal dysplasia. Vet. Pathol. 24 (2): 156-163.

Rabelo, E.; Oliveira, E.; Silva, J.; Oliveira, D. and Colosimo, E. (2006): Ultrasound progression of prenatally detected multicystic dysplastic kidney. Urology 68 (5): 10981102.

Rademacher (2005): Starke Kolik bei einer Kuh mit Pyelonephritis. Tierärztliche Umschau 60: 291-293.

Ridson, R.A. (1971): Renal dysplasia; Part I A clinicopathological study of 76 cases. Clin. Pathol. 24 (1): 57-71.

Sasaki, Y.; Kitagawa, H.; Kitoh, K.; Okura, Y.; Suzuki, K.; Mizukoshi, M.; Ohba, Y.; and Masegi, T. (2002): Pathological changes of renal tubular dysplasia in Japanese Black cattle. Vet. Rec. Vol 150, Issue 20, 628-632

Schmidt, I.M.; Main, K.M. and Damgaard, I.N. (2004): Kidney growth in 717 healthy children aged 0-18 months: a longitudinal cohort study. Pediatr. Nephrol. 19: 992-1003

Schulze, C.; Meyer, H.P. Blok, A.L. Schipper, K.; van-den Lngh, T.S. (1998): Renal dysplasia in three young adult Dutch kooiker dogs. Vet. Quebec. Canada. 20 (4): 146-148

Tyler, J.W.; Smith, B.F. and Irvine, J. (1991): Hydronephrosis and pyelonephritis associated with an anomalous vas deferens in a bull. J. Amer. Vet. Med. Assoc. pp 198.

Walter, P.A.; Johnston, G.R.; Feeny, D.A. and O'Brien, T.D. (1988): Applications of ultrasonography in the diagnosis of parenchymal kidney disease in cats. J. Am. Vet. Med. Assoc. 192: 92-98

Wood, A.K. and McCarthy, P.H. (1990): Ultrasonographicanatomic correlation and an imaging protocol of the normal canine kidney. Am. J. Vet. Res. 51 (1): 103-8. 



$$
\text { الفحص بالموجات فوق الصوتية للكلى الطبيعية والمتحوصلة والضامرة في الأبقار }
$$

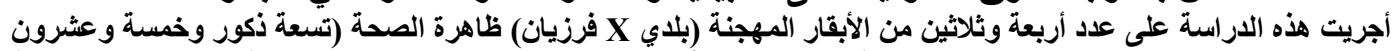

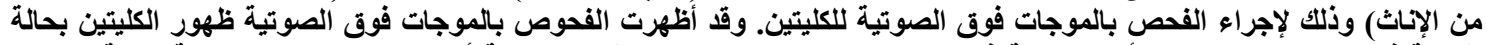

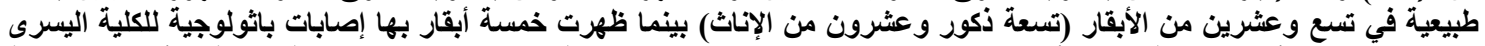

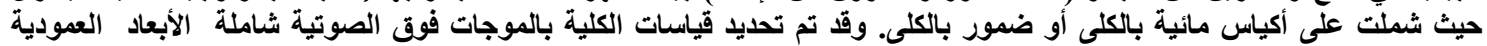

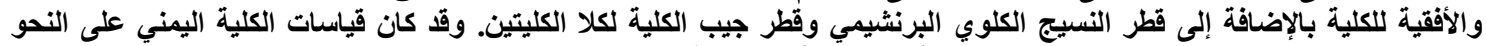

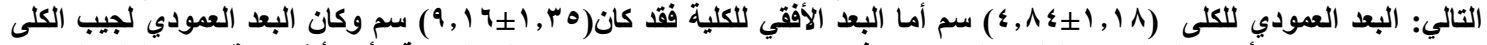

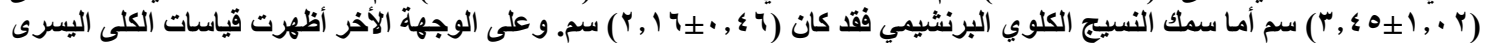

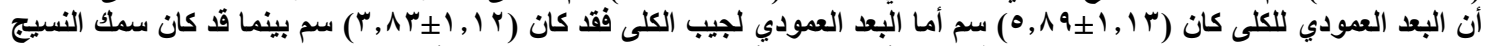

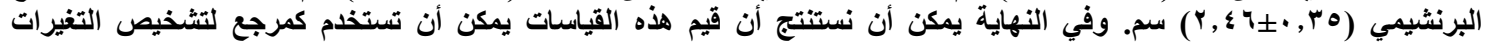
المورفولوجية للكلية في الأبقار المحليةً المهجنة مع الأبقار الفززيان. 